\title{
Retraining Professional Management Personnel at Coal Industry Enterprises: the Requirements of the Time
}

\author{
Marianna Gorbatova ${ }^{1}$, Alexey Gorbatov ${ }^{2}$, Alexander Pyanov $^{3}$, and Albina Levanova ${ }^{4, *}$ \\ ${ }^{1}$ Kemerovo State University, Department of Psychological Sciences, 650000 Ulitsa Krasnaya 6, \\ Kemerovo, Russian Federation \\ ${ }^{2}$ Kemerovo State University, Department of World History and Socio-Political Sciences, 650000 \\ Ulitsa Krasnaya 6, Kemerovo, Russian Federation \\ ${ }^{3}$ Kemerovo State University, Department of Russian History, 650000 Ulitsa Krasnaya 6, Kemerovo, \\ Russian Federation \\ ${ }^{4}$ Kemerovo State University, Department of Foreign Languages in Professional Communication, \\ 650000 Ulitsa Krasnaya 6, Kemerovo, Russian Federation
}

\begin{abstract}
The article is devoted to the analysis and evaluation of the existing approaches to the system of retraining and development of middle level managers of mines and opencast mining sites of the region. Increase of the overall performance of coal industry enterprises requires a more advanced system of retraining of operational and managerial personnel. Based on the historical experience of professional training of previous years, we attempted to propose an approach to organizing the process of professional development that meets the requirements of the time. Tasks for improvement of professional skills and priority areas of training were identified based on analytical data of group questionnaires. A series of indepth interviews with top managers of coal enterprises made it possible to determine the existing level of training; the content analysis of documents was used to study the content of programs, forms and methods of training; a survey was conducted to determine the level of critical knowledge of employees who received training over the past year.
\end{abstract}

\section{Introduction}

January 24, 2012 in the city of Kemerovo, a meeting "On the results of restructuring and prospects for the development of coal industry" was held. Following the event, the Chairman of the Government of the Russian Federation V. V. Putin signed a Government Decree approving a long-term program of development of coal industry in Russia up to 2030. It is based on a systematic approach. Its implementation, according to Vladimir Putin, will ensure the development of one of the basic branches of the domestic fuel and energy complex - coal industry.

Among the numerous directions stated in the target program, a special place is occupied by the section on training professional personnel for the coal mining industry in the region.

\footnotetext{
* Corresponding author: levanova@bk.ru
} 
An effective system of vocational education is recognized as an indispensable requirement for achieving such key indicators of the industry development as the growth of coal production, investment, and a significant increase in labor productivity.

The program identifies two directions of the reform of the system of personnel training: the development of the education system and the reform of the system for upgrading the skills of workers in the industry.

To achieve the first set of goals, special measures are planned to develop targeted admission to institutions of secondary and higher professional education. Moreover, development and introduction of distant and modular forms of training of workers is stipulated in the coal industry as well as involvement of scientists and specialists of higher educational institutions in the advancement and implementation of programs for the development of industrial science. To ensure steady and continued access to qualified labor investments are assigned into the establishment of certification centers for professional qualifications and creation of mechanisms for the integration of universities and specialized scientific organizations to provide fundamental and innovative nature of training. Material resources are allocated for the implementation of educational programs for the training of personnel for the coal industry [1].

\section{Materials and Methods}

The reformation of the system of professional development of personnel in the industry includes a number of measures aimed at a significant increase in labor productivity [2-4]. These include the introduction of a legislative standard on mandatory upgrading the skills of specialists and managers in the establishments of coal industry. Special emphasis is made on creation of programs of advanced training for operational and managerial personnel to meet the demands and needs of the branch; development and implementation of distance and modular forms of retraining and advanced training of workers in the coal industry.

One of the features of a systematic approach to the development of a particular sector of the economy is that the program includes planned key results. Thus, in the field of development of vocational and advanced training of coal industry workers by 2030, the following indicators are expected to be achieved: bringing the proportion of workers who meet professional qualification requirements to 100 percent; increasing the number of scientific and technical workers to 20 people per 1 million tons of coal production. Furthermore, young professionals, trained to meet coal market demands through targeted admission to secondary special and higher educational institutions, will ensure innovations in developing and applying new technologies and procedures at coal industry establishments.

Setting ambitious goals for providing the industry with $100 \%$ professional staff in such a short time requires, in our opinion, turning to the positive experience of the Soviet era. In the 1930 -s, under the conditions of the accelerated development of the coal mining industry, the leadership of the USSR also faced the problem of shortage of qualified labor in mines and opencast mining sites. The solution of the skilled labor shortage problem was the implementation of the whole system of measures. One of its key directions was the creation of a broad network of schools designed to provide training for workers on the ground. So, at the turn of the 1920s-1930s, vocational training and professional development of specialists were carried out by the schools of mining apprenticeship (Gorpromuch) factory and construction apprenticeship (FZU, Stroyuch), as well as through various courses of on-thejob training. In the 1960 s, the country and the coal mining branch once again faced the challenge of training and retraining workforce due to the dramatic changes in coal mining technologies and the introduction of achievements of scientific and technological progress. Under these conditions, the need for better-qualified labor and specialists with a better education, rather than what was provided by the FZU, became especially apparent. The 
transition to vocational schools (PTU) where the term of study significantly increased (up to 3-4 years), based on 8 years of school education, allowed to train specialists that are more qualified. The system of vocational schools existed with minor changes until the period of market transformation of the Russian economy and provided the coal industry of the country with qualified labor.

The reforms in the economy and social sphere, the decline in production in all sectors, including coal mining, which began in the early 1990-s, led to a crisis in the system of vocational training. At the time when the mines closed, specialists were forced to leave the profession. Mining specialties lost status, the government of the Russian Federation adopted resolutions determining the main directions of training personnel in a market economy.

Positive trends in the coal industry, which took shape in the first half of the 2000 s revealed a new problem. Construction, modernization and technical re-equipment of coal enterprises by new owners faced acute shortage of qualified operational and managerial staff. Many researchers have repeatedly pointed out that companies that invest in a well-trained and certified workforce at all levels continue to stay ahead of the curve and remain competitive [5-7]. So, increasing the efficiency of mining enterprises today sets the task of making a new technological breakthrough [8], which requires diversifying interaction of educational institutions with enterprises and organizations of the region, building a better system of training and retraining highly qualified workforce for coal mining enterprises [9-10].

\section{Results and Discussion}

The experience of long-term cooperation with the coal industry enterprises within the framework of organizational consulting allowed us to analyze and summarize the existing approaches to setting up a system for retraining and advanced training of personnel of mines and open cast mines of the region. We consider investing in front-line employees for improvement of their skills a key component of the personnel policy of the organization.

The authors carried out a research to analyze and evaluate the current approaches to the system of workforce cultivation efforts and mid-level management at the coal enterprises of the region. The following methods were applied to collect data:

1. In-depth interviews with top management of enterprises to assess the current level of training and the formation of goals and objectives of training.

2. Group interviews with employees to determine the need for training and priority areas of training.

3. Content analysis to study the content of training programs and their compliance with the strategic goals of the company.

4. Analysis of documents to obtain information on the forms and methods of instruction.

5. Questionnaires to determine the level of critical knowledge of employees who have undergone training in various areas over the past year.

During the period from 2008 to 2012 (i.e. before the adoption of the coal industry development program), 37 group interviews were conducted with 396 managers. In addition, over 50 individual interviews took place with mid-level managers and top managers of coal enterprises; about $70 \%$ of employees who completed training over the last year at the time of the survey took part in the questionnaire.

According to the provisions of a number of regulatory documents on the training and professional development of staff of more than 10 coal enterprises, middle-level managers must undergo external long-term basic management training every 5 years. Additionally, training in management topics in short-term courses and workshops should be organized once every 2 years, training on short-term professional programs, participation in targeted seminars, visits to conferences on their profile of activities - once a year, intercorporate seminars - once a year. 
However, the majority of respondents stated during the interview that this provision is not currently fully implemented. Most middle-level managers got their training outside Kemerovo region, mainly in Moscow, St. Petersburg, in resort towns or abroad. As proved by the analysis of financial and accounting documents, the cost of implementing off-site training programs exceeds the cost of local training by two and more times.

Accordingly, the vast majority of the funds allocated for this expenditure item were spent on field training programs. The advantages of off-site training programs are most often argued that such programs are effective in terms of sharing experience, familiarity with new technologies, a new view of the problem, etc.

However, many respondents explicitly stated that the practice of preferential referral to off-site training programs is in most cases "incentive", and the system for assessing the effectiveness of the training undertaken does not actually exist.

Therefore, in the course of our research, we studied the subjective assessment of residual knowledge (as a percentage) based on the results of training, as well as subjective satisfaction with the training on the following parameters: compliance with their own professional needs, novelty and applicability of the acquired knowledge in practice.

Training programs implemented in local educational centers are more suitable for production needs, and the knowledge gained in them is much more durable and applicable in practice. Off-site training programs benefit only in terms of the "novelty", which can be explained by the very fact of separation from production and a change in the cultural environment.

In many cases, they are not sufficiently aware of the strategic objectives of their enterprises, of the requirements that stem from the urgent tasks of their development. Another often-called problem, common to both middle-level managers and their superiors, is the lack of information about existing programs, forms and methods of training. As follows from the results of the study, the choice of training programs for middle-level managers is not based on the training needs of a particular category of employees, but on the information that is currently available to a particular leader.

All this confirms the fact that most managers find it difficult to characterize the overall system of training and development or state only the presence of its individual elements.

Thus, the organization of training and development is characterized by a contradiction between the requirements to personnel following from the strategic objectives of reforming the branch and the operating system of training, which is based on the old principles. The conducted research of the training system based on a number of coal-mining enterprises of the region allows us to come to the following conclusions of the ascertaining nature:

- the existing training practice does not generally meet modern requirements and lacks consistency;

- middle-level managers do not clearly understand the strategic goals of the company, or are completely unaware of them, which naturally hinders the actualization of the need for the necessary training areas.

- There is a sharp predominance of training in the narrow professional profile, which indicates that middle managers are not perceived as professional managers.

- Costly, expensive training programs are distinctly dominant, having a pronounced "incentive" character.

- There is no system for assessing the effectiveness of staff training.

- Training costs in most cases do not correspond to the actual effectiveness of specific programs. Moreover, the dependence between the cost of training and subjective assessment of residual knowledge, novelty, and practical applicability is, in most cases, reversed.

- There is no unity in determining priority areas of training for the same categories of employees working in different divisions. 
- The individual level of preparedness, experience are not taken into account, when choosing retraining programs, the career plan for employees is not worked out.

- In spite of the fact that the "Regulations for training and development of personnel" have been developed and implemented at all enterprises, the requirements stipulated in them for the periodicity of training and advanced training are not observed in practice.

- Unit managers do not have sufficient information on the existing programs, forms and methods of training. The choice of programs is carried out by means of stereotyped reproduction of last year's applications, or is random.

The basis for the organization of the training system for the period of reform should be a kind of prohibition on the implementation of the majority of expensive off-site programs before conducting research in the field of educational services and before developing a system for assessing the effectiveness of the completed training. We recommend focusing on the training programs offered by local training centers, as well as enterprise managers. The condition for the implementation of the proposed recommendations is compliance with the following principles:

1. The transition from the use of training as a tool of encouragement to the means of development of personnel and the enterprise as a whole.

2. The system of personnel training at all levels should be based on the structural model of the psychological readiness for security activities at hazardous production facilities.

3. Creation a system of motivation for learning. Link vocational training with the evaluation and staffing.

4. The shift of emphasis from narrowly professional to managerial training programs.

5. Standardization of common approaches and directions of training in job categories.

6. Expanding the scope of training programs for the acquisition of knowledge in related areas of activity.

7. The choice of training programs based on not only the position held, but also taking into account the career plan of the employee.

8. Creating a system of information exchange between top managers and middle-level managers on the goals, objectives, and intermediate results of development, both individual enterprises and the industry as a whole.

9. Organization of a system of experience exchange both within each job category and among different structural units of the industry

10. Activation of "mentoring" Institute for new employees.

11. Adopting a regulation for the heads of structural units on informing of the new approaches to the training system, the capabilities of specific educational institutions.

12. Reducing the costs of training by attracting leading experts and specialists in the territory and organization of on-line training.

13. Involving qualified specialists from among the employees of the enterprise for instruction at the leading training courses along with invited experts.

14. Compliance with the requirements for the timing and frequency of retraining and continuing education.

\section{Conclusion}

Currently, coal remains the largest source of energy in Siberia, providing many jobs, employment opportunities and economic growth for coal mining enterprises. In these circumstances, it is important to understand that the mechanism of management should be based on an innovative approach to training and retraining middle-level management to increase the efficiency of the enterprise. The implementation of these principles, the application of modern requirements and actual tasks of reforming the industry have enabled a number of coal enterprises in the region [11] to build well-designed and built-up personnel 
management systems benefiting from a better-trained workforce which have managed to adapt to the changing needs of the market environment.

\section{References}

1. Z. Schlanger, Energy Shocks. Coal miners are so confident Trump will bring coal back that they're rejecting alternate career retraining (Media LLC, New York, 2017)

2. G. C. Gonzalez, R. Singh, R. Karam, D. S. Ortiz, Energy-Sector Workforce Development in Southwestern Pennsylvania. Aligning Education and Training with Innovation and Needed Skills (Media LLC, New York, 2014)

3. L. Schroeder, Getting in on the Ground Floor (Media LLC, New York, 2015)

4. R. Krishnanand, Penn Energy Jobs, 2, 2-7 (2014)

5. I. Kobersy, K. Barmuta, S. Muradova, L. Dubrova, D. Shkurkin, Mediterranean Journal of Social Sciences, 6:3S4, 25-30 (2015)

6. T. Strickland, G. Dotson L. A. Matt, Revitalizing Appalachia: How Congress Can Correct Distortions in the Coal Market and Invest in Struggling Coal Communities (Center for American Progress, Washington, 2014)

7. L. J. Richardson, R. Cleetus, S. Clemmer, J. Deyette, Environ. Res. Lett., 9, 024006 (2014)

8. D. Benton, The future of coal in the heart of Botswana (Mining, Berlin, 2018)

9. G. E. Conrad, Mine Reclamation Bonding - from Dilemma to Crisis to Reinvention: What's a State Regulator to Do? (Foundation Winter Workshop on Energy Law, Trenton, 2014)

10. National Mining Association, The Economic Contributions of U.S. Mining, 2011 (MCUT, Chicago, 2012)

11. I. G. Cherepanova, Ugol', 4, 9-13 (2016) 